Tempo Social; Rev. Sociol. USP, S. Paulo, 9(1): 79-94, maio de 1997.

\title{
Observações sobre a falência dos modelos policiais
}

MARCOS LUIZBRETAS

RESUMO: O trabalho busca apontar como em diferentes contextos nacionais a polícia se estruturou de formas burocráticas diversas, mas que, ao mesmo tempo, a experiência organizacional produziu agentes policiais com visões de mundo bastante semelhantes. Polícias sob o controle de governos centrais ou locais são ocupadas por pessoal que se expressa da mesma forma. $\bigcirc$ artigo oferece como hipótese que isso se deve às experiências diárias comuns a todos os sistemas policiais, fazendo da atividade cotidiana o foco da compreensão das práticas policiais. Em seguida, como exemplo, o trabalho busca analisar a prática da polícia carioca no início do século $X X$, em seus contatos com membros das elites, mostrando como essas práticas produzem, ao mesmo tempo, os limites da autoridade policial e a percepção das áreas onde seu poder pode ser exercido de forma extralegal.

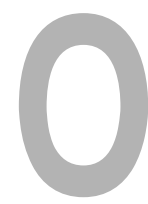

que vamos buscar fazer neste trabalho é sugerir alguns elementos de diferenciação entre as diversas formas de polícia desenvolvidas em contextos nacionais, tentando ao mesmo tempo demarcar o espaço interno - cultural - de unidade entre elas, procurando verificar como esta unidade se constrói a partir de diferentes experiências - ou sugerir que talvez estas experiências não sejam tão diferentes assim. O estudo de polícias enfrenta sempre esta dificuldade, de demarcar a especificidade de sua posição numa nação, com um ordenamento administrativo e jurídico específico, ao mesmo tempo que possui um elemento comum, transnacional, reconhecível em realidades as mais diversas. Parte deste problema se origina da dificuldade em definir o que é a polícia, além de um objeto comum de ação
UNITERMOS: polícia, organizações, visões de mundo, elites.

Fundação Casa de Rui Barbosa-RJ 
no combate ao crime (cf. Cain, 1992, p. 3-32) ${ }^{1}$. Estudos comparativos de organização policial caem num labirinto de minúcias históricas ou legais, talvez de difícil e pouco útil compreensão (cf. Bayley, 1992, p. 509-546), enquanto uma identidade policial muito mais clara é possível através dos estudos de cultura ou de mentalidade policial. A leitura de depoimentos de policiais sobre a forma de encarar sua atividade, por exemplo, produz uma forte impressão da existência de uma comunidade, em que as definições empregadas são muito semelhantes, mesmo em polícias organizacionalmente as mais diversas.

Quando se fala em polícia, trabalhamos normalmente com uma idéia geral, aplicável à sociedade moderna como um todo; sem que se discuta o que existe de específico e o que é geral nessa idéia em circunstâncias particulares. Mesmo através da moderna cultura de massa, especialmente o cinema, elaborou-se uma imagem policial que é facilmente identificável, ao menos no quadro do Ocidente ${ }^{2}$. Esta polícia genérica faz com que seja extremamente difícil consolidar uma definição do que é a polícia, pois encobre as características específicas e faz o conceito parecer óbvio; isto é, como a polícia é sempre imediatamente identificável, não há nenhuma dúvida sobre o que ela é ou faz. Este problema ganha importância num momento de crise da solução policial, como o que é vivido em grande parte deste mundo ocidental a partir dos anos 60, e tem sido particularmente sensível no caso brasileiro da década de 80. Ao mesmo tempo em que se clama contra a falência da polícia, existe uma dificuldade imensa em pensar alternativas, na medida em que a idéia genérica de polícia permanece. A fórmula utilizada tem sido em geral clamar pelo "mais do mesmo", quer dizer, para resolver a crise são necessários mais policiais, penas mais duras, etc. O principal apoio para esta formulação vem da própria polícia; se formos buscar o que existe de comum entre as diferentes formas de polícia, uma primeira característica a apontar poderia bem ser a resistência a inovações.

O nome polícia se generalizou nos países ocidentais de uma forma enganosa, pois sob o mesmo nome podem aparecer instituições com formas e atribuições muito diversas. Não cabe aqui fazer uma história do termo polícia, mas antes precisar o seu significado histórico: a polícia nas linhas gerais que se associam com a idéia moderna se origina das instituições ligadas ao estado francês do século XVII, que se espalham pelas monarquias absolutistas similares, como Portugal e daí para o Brasil, ou mais tarde, a partir da expansão napoleônica, pelo próprio emprego de forças policiais pelo invasor francês, em seguida conservadas pelos governos de restauração. Numa linha um pouco diversa aparecem as polícias dos países anglo-saxônicos, onde a instituição policial aparece marcada por um forte desejo de diferenciar-se do referencial francês - de fato em oposição a este - o que de alguma forma mantém ainda o modelo francês como referencial ${ }^{3}$. A diferença adotada é, ao menos num primeiro momento, um maior número de restrições seja ao escopo da ação policial seja aos recursos disponíveis pela polícia no controle da população. Desde sua criação, a polícia inglesa vem buscando formas de reduzir 
essas limitações de origem ${ }^{4}$.

Esse resumo da formação da polícia moderna, porém, preserva o engano notado acima, sugerindo uma unidade de resultado que não existe na realidade. Talvez fosse possível sugerir uma unidade de práticas no campo da manutenção da ordem pública, mas as formas tomadas pelas instituições variam muito. A distribuição pelo território nacional pode ser mais ou menos extensa, algumas polícias importam a estrutura militar, a ênfase no uniforme é maior ou menor, o controle da força é conservado em nível local ou não, a atuação privilegia o cumprimento de normas definidas ou concede maior poder ao discernimento do policial no cumprimento de suas tarefas. Apesar de toda a variação institucional, porém, parece haver a formação de uma cultura profissional coletiva, o que David Bayley chama "Zeitgeist internacional e profissional".

Assim como a criminologia positivista propôs a mudança de enfoque do crime para o criminoso, parece proveitoso sugerir uma passagem do estudo da polícia para o estudo do policial. É aqui que se estruturam os significados que conformam a ação policial, em grande parte independendo de estruturas organizacionais, tantas vezes reformadas sem alcançar resultados efetivos. Não é recente o interesse que os estudiosos da polícia dedicam ao estudo da cultura policial; desde os elementos clássicos definidos por Jerome H. Skolnick ao analisar a working personality dos policiais, são muitos os estudos que se dedicam ao tema. É possível elaborar um pouco mais as categorias definidas por Skolnick, mas sob o risco de perder exatamente o elemento genérico que venho tentando enfatizar na definição do agente policial. Na versão de Skolnick, o centro da experiência policial giraria em torno da combinação de perigo e autoridade, em que a presença do perigo colocaria em risco o discernimento necessário para o uso da autoridade. Assim a adesão policial às normas legais variaria de acordo com o perigo a que os mesmos são expostos. Utilizando dados referentes ao julgamento de policiais na cidade inglesa de Sheffield acusados de espancamento, Skolnick oferece depoimentos que poderiam ser colhidos em qualquer delegacia brasileira: "que os tribunais tratam os criminosos de forma muito branda; que os criminosos não respeitam as leis e a polícia precisa e deve fazer o mesmo para chegar na frente; que a força é aceitável como um último recurso de investigação quando os outros métodos falham e uma boa surra é o único meio de desviar um criminoso de sua vida de crimes" (Skolnick, 1966, p. 68)5. Para marcar algumas distinções seria preciso notar a ressalva - quando falham os métodos normais - e também que estes policiais foram punidos; mas a presença crescente de ameaça teria provocado a radicalização/degeneração da autoridade.

Parece claro, neste ponto, que existe uma cultura policial que não obedece a limites nacionais, mas cujos efeitos em determinar comportamentos destas forças são limitados, o que ocorreria segundo Skolnick devido ao grau de perigo enfrentado em cada caso particular. Entre as características desta cultura têm sido enumerados o conservadorismo, o cinismo ou 
pessimismo, o preconceito racial, a suspeita e o isolamento da comunidade contrabalançado por um sentimento de solidariedade de grupo e outros ${ }^{6}$. Este conjunto de elementos produz uma visão preferencialmente negativa do mundo que lhe é exterior - reflexo do tipo de evento que lhes é apresentado diariamente - incluindo aí o sistema legal como um todo, que deixa escapar delinqüentes que a polícia poderia pegar com facilidade se não tivessem de respeitar os limites legais. "A polícia prende e a justiça solta" é um argumento permanente de policiais. As diferenças locais não se fazem pelo que os policiais pensam, mas por quanto deste pensamento é transformado em ação.

Enquanto em certos países a polícia responde a pressões da sociedade e de governos para respeitar certos limites, e casos como Sheffield são vistos como desvio de uma norma, em outros pode-se dizer que o desvio é a norma. Antes de entrarmos mais detalhadamente em características do caso brasileiro, podemos buscar confirmações em outros países que enfrentam situações semelhantes. Para ouvidos brasileiros soa extremamente familiar esta lista de práticas policiais:

1. empregam meios injustos para obter confissões;

2. não têm vergonha de roubar objetos da cena do crime;

3. forjam evidência em casos criminais;

4.mentem nos tribunais;

5. instruem as testemunhas e produzem falsos testemunhos;

6. usam da violência no "xadrez" das delegacias;

7. usam meios desonestos para tirar dinheiro das pessoas;

8. mantêm presas pessoas além do período permitido porlei;

9. recusam aos presos o contato com os advogados de sua escolha;

10. acobertam as queixas contra eles;

11. fazem prisões informais, ilegais e arbitrárias;

12. pressionam as famílias dos presos;

13. cometem tortura, estupro e assassinato de pessoas sob custódia;

14. usam palavrões e linguagem indecente;

15. humilham as pessoas e degradam os detidos;

16. deixam os detidos passando fome e os conduzem à opção indesejável do suicídio;

17. algemam os presos e os acorrentam no "xadrez", além de exibi-los acorrentados em público quando conduzidos aos tribunais.

Essa descrição familiar refere-se à polícia da Índia (cf. Vadackumchery, 1996, p.73-74), mas com maior ou menor flexibilidade pode se assemelhar a 
muitas outras polícias. Certamente a experiência colonial compartilhada por Brasil e Índia tem efeitos específicos na constituição das polícias, como acentuou Mike Brogden, mas a diferença talvez seja apenas de grau, representando um elemento que permite utilizar mais livremente a autoridade policial, assim como o grau de perigo mencionado por Skolnick (cf. Brogden, 1987, p. 4-14; Palmer, 1988).

Finalmente, entre os elementos que conduzem a maior ou menor liberdade no emprego do poder concedido às polícias, é preciso levar em conta a pressão exercida, seja pelo poder público, seja pela sociedade. Comentando este ponto, Reiner sugere que boa parte da pressão popular pode ser reflexo de uma manipulação policial, mas tal hipótese, que pode ser legítima na sofisticação das manobras políticas inglesas, tem alcance muito mais limitado em contextos como o brasileiro. Neste caso, o que parece ter ocorrido é uma pressão por parte dos setores mais altos da sociedade pela solução de problemas que eram postos na esfera policial, sem que ao mesmo tempo tenha havido uma interferência do Estado de porte a conformar as práticas policiais ${ }^{7}$. Mesmo a pressão vinda de cima deve ser tomada de forma cautelosa; se a grande questão policial é o combate ao crime, esta não parece ser uma preocupação importante para as elites brasileiras, pelo menos até muito recentemente.

Teria ocorrido, então, um desenvolvimento da cultura policial, a partir das suas experiências cotidianas, sem que fosse acompanhada pela elaboração de formas de controle ou limitação de sua capacidade de ação, gerando um espaço onde os desejos policiais de autoridade podem ser satisfeitos sem peias. Existe apenas um aparato legal que supostamente ditaria os limites da ação policial, mas que não funciona na prática, a não ser para oferecer aos policiais razões aparentemente legítimas para não agir de formas que eles não desejam $^{8}$. É na atividade cotidiana dos policiais que podemos buscar as origens de seu saber, que ainda permanece largamente informal, distinto do treinamento que mais e mais se tenta oferecer nos centros de instrução. Se existe hoje uma preocupação acentuada em oferecer a novos policiais um treinamento mais adequado e melhor direcionado para temas como respeito aos limites legalmente estabelecidos de sua atuação, um dos pontos mais difíceis de quebrar será certamente o outro aprendizado, que é oferecido quando o novo policial passa da escola a rua, onde as verdades da profissão são apresentadas de forma muito diversa.

O espaço disponível aqui permite apenas que se apresente alguns exemplos da constituição desse saber informal, através do acompanhamento de situações onde ele se origina. A busca de raízes históricas oferece uma alternativa à dificuldade em acompanhar esse "treinamento" na sua forma diária moderna da transmissão do saber dentro das delegacias e quartéis. Num momento de formação da polícia como profissão, que ocorre durante a primeira metade do século XX, esse aprendizado repousa ainda mais sobre a experimentação e o erro, e pode ser acompanhado através dos registros de ocorrência das delegacias policiais. Utilizarei aqui como exemplo a definição 
de como a polícia aprende a se relacionar com elementos da elite, tarefa que deve ser das mais complicadas, por colocar em evidência a precariedade da suposta autoridade policial, especialmente no quadro clientelístico que caracteriza o Estado brasileiro.

Como sempre, o alvo preferido da vigilância policial era o cidadão comum. Não era tão simples quando esse "cidadão comum" não era tão comum. Se realmente existem assuntos impenetráveis ao exame do historiador, o policiamento das classes superiores da sociedade é um sério candidato. Desde a criação das modernas corporações policiais, presume-se que as classes superiores devem ser protegidas e não policiadas. Isso não quer dizer que os "respeitáveis" não pratiquem delitos, mas que a maioria de suas transgressões fogem aos procedimentos tradicionais da polícia. Os mais típicos desses delitos, chamados nos anos 1930 por Edwin Sutherland de "crimes de colarinho branco", não têm nada a ver com policiamento ostensivo ou com delegacias policiais, e são controlados principalmente por outros órgãos que não a polícia.

Existem, entretanto, alguns casos em que esses grupos se defrontam com a polícia, e, estatisticamente falando, eles podem até ser superrepresentados, como Rob Sindall sugeriu referindo-se à classe média da Inglaterra vitoriana (Sindall, 1983, p. 23-40). Contudo, o número concreto dessas transgressões é muito pequeno, e elas não são identificadas pela polícia como um problema. O mesmo tipo de atitude é evidente nas causas célebres, mais facilmente localizáveis, especialmente os crimes passionais ${ }^{9}$, embora chamem a atenção da imprensa e possam ocupar as histórias do crime mais tradicionais, não são representativos do trabalho da polícia ${ }^{10}$.

Dois tipos de ocorrências foram descritos como tendo aproximado a polícia das classes superiores no século XX: a emergência do automóvel e a criminalização dos entorpecentes. O rápido aumento no número de carros, circulando em ruas que não tinham sido construídas para eles, criou novas modalidades de perigos urbanos e uma nova preocupação para a polícia. Mas o que o carro trouxe para a polícia brasileira foi a figura do motorista e às vezes de seu ajudante, raramente a do proprietário do carro, membro da classe alta. Havia uma acentuada diferença no Rio entre o dono do carro e seu motorista - uma nova profissão emergente - que mantinha a polícia afastada dos primeiros ${ }^{11}$. Os proprietários só apareciam, em geral, como testemunhas quando seus motoristas atropelavam alguém ${ }^{12}$, ou como queixosos contra outros motoristas que tinham danificado seus carros ${ }^{13}$.

O problema do consumo de drogas e de sua criminalização no início do século XX nem sempre esteve ligado à elite, mas um estudo médico do assunto significativamente escolheu o título Vícios sociais elegantes (cf. Pernambuco Filho \& Botelho, 1924) $)^{14}$. Havia uma longa tradição de preocupação com o alcoolismo entre os pobres, e também havia um certo cuidado com as casas de ópio chinesas ${ }^{15}$; mas as drogas que concentravam maior atenção nos anos 1920, quando o comércio de drogas foi devidamente criminalizado, eram a cocaína e a morfina: "iniciando suas conquistas pelas classes 
elevadas, a cocaína já vazou para os andares mais inferiores da sociedade e, na sua torrencial caminhada, começa a envolver criados, operários e pessoas menos abastadas" (Pernambuco Filho \& Botelho, 1924, p. 27) ${ }^{16}$. Eram freqüentes os casos de venda ou consumo de cocaína, mas, nas delegacias, eles raramente envolviam membros da elite. Ao contrário, a repressão às drogas se concentrava na prostituição, meio no qual a polícia encontrava o principal grupo consumidor ${ }^{17}$. Em 20 de agosto de 1921, por exemplo, a polícia registrou a prisão de Fernando Henrique, um português de 22 anos, que oferecia cocaína às meretrizes da rua das Marrecas $22^{18}$.

Se as classes altas não aparecem nos registros associadas aos principais tipos de delitos que lhes são mais freqüentemente atribuídos, como aparecem então? Sua presença nos registros de ocorrências pode ser analisada através de seus papéis de vítimas, de patrocinadores de terceiros e nos raros incidentes em que se envolviam em desordens.

Embora há muito tenha sido estabelecido que a maioria das vítimas de delitos pertence aos mesmos grupos sociais dos autores do delito, as camadas sociais superiores muitas vezes também eram vítimas. Eles não eram vítimas dos crimes mais comuns contra a pessoa, a menos que o delinqüente fosse do mesmo grupo social, mas eram objeto de crimes contra a propriedade. O perfil social das vítimas nos registros é muito difícil de ser estabelecido; elas não eram devidamente identificadas, embora em alguns casos encontremos sinais de deferência em títulos como "doutor" ou "madame”. Mas os símbolos mais úteis da posição social das vítimas eram o tipo de bens roubados e as medidas tomadas pela polícia. Os primeiros são mais evidentes em casos de roubo contra firmas, particularmente arrombamentos, em que os proprietários eram considerados como especialmente merecedores da atenção da polícia.

As medidas tomadas pela polícia ficam claras após uma tentativa de roubo na casa do caseiro do senador Pinheiro Machado, na época um dos políticos mais influentes do país. Ao contrário de todos os procedimentos em casos semelhantes, três agentes foram designados para a investigação ${ }^{19}$. Os recursos da polícia podiam ser colocados à disposição de pessoas influentes, mesmo quando não se justificava sua intervenção. Na noite de 25 de junho de 1923, no Teatro Municipal, a esposa do ministro do Supremo Tribunal, Godofredo Cunha, perdeu um crucifixo de diamantes estimado em 1:500\$000. Embora o próprio ministro tivesse deixado claro que a jóia tinha sido perdida e não roubada, uma turma de guardas civis foi incumbida de vasculhar o teatro e as ruas próximas ${ }^{20}$.

O relacionamento entre a polícia e as classes superiores nunca foi confortável. Mesmo quando representantes da elite desempenhavam o papel de queixosos, os policiais ficavam em posição difícil. Queriam agradar ${ }^{21}$, mas suas boas intenções eram prejudicadas pela escassez de recursos e pelo fato de não terem o controle absoluto dos acontecimentos. As vítimas podiam recusar assistência médica, suicídios eram dispensados das formalidades médico-legais ${ }^{22}$, e mesmo casos sobre os quais não pairavam dúvidas podiam 
ser sustados. Embora as vítimas pudessem desistir de seus casos, não era aconselhável ao comissário ignorar as queixas feitas por representantes das classes superiores. Quando a Sra. Coelho Barreto compareceu ao $5^{\circ} \mathrm{DP}$ para registrar queixa de furto contra uma empregada, ela não ficou satisfeita com o atendimento:

Eram pouco mais de 6 horas quando a Sra. Coelho Barreto entrou na delegacia.

Recebeu-a o estremunhado prontidão.

- Que quer?

- Desejava falar com o delegado.

- Não é hora, a senhora venha ao meio-dia.

- O caso é urgente, senhor; desde que não está o delegado falarei com a pessoa que o substitui.

- É o comissário mas ele está dormindo.

- Tenha a bondade de chamá-lo. Esperarei.

A senhora espera pacientemente uma hora, no fim da qual viu aparecer bocejante a porta de um pequeno quarto a figura cansada e preguiçosa da mais completa autoridade policial $^{23}$.

O comissário Braga saiu-se muito mal na imprensa, o que não chega a ser surpresa, pois a vítima era cunhada do diretor do Jornal do Commércio, Ernesto Senna, e mãe de João do Rio, um dos jornalistas mais respeitados da época. Durante semanas a fio o Jornal do Commércio desfechou uma campanha contra "quão pouco e quão mal se cumprem [na polícia] atualmente os deveres regulamentares na maioria dos casos", a despeito dos esforços do Chefe de Polícia ${ }^{24}$.

Se ter as classes superiores no papel de vítimas já acarretava problemas para a polícia, a situação tornava-se ainda mais complicada quando elas se apresentavam como fiadoras de vítimas ou de acusados. Numa sociedade na qual as boas relações eram essenciais para definir a posição social de um indivíduo, era de bom alvitre para uma vítima comparecer à delegacia acompanhada por um deputado ${ }^{25}$. No seu cotidiano, os policiais tinham muitas oportunidades de encontrar partes mais ou menos interessadas, e que podiam alterar o perfil de um caso. Quando o $5^{\circ}$ Distrito recebeu um telefonema, às 2 horas da manhã, da sociedade carnavalesca Tenentes do Diabo informando que um grupo de estudantes pretendia forçar a entrada e provocar desordens, o comissário foi até o local ver o que estava acontecendo. Foi recebido por um deputado "que declarou nada haver e que responderia pelos rapazes". Mesmo assim, o comissário deu ciência ao delegado e ao delegado auxiliar de serviço, comparecendo ao clube o delegado do distrito para serenar os ânimos. Mais tarde, os estudantes voltaram e trocaram tiros com a segurança do clube, ferindo um guarda civil que estava em patrulha ${ }^{26}$.

Uma situação capaz de resultar em prisão sempre podia ser alterada pela intervenção de um espectador bem intencionado, não-profissional; em 
casos de violência praticada pela polícia, era frequiente encontrar pessoas que telefonavam ou compareciam à delegacia para registrar queixas ${ }^{27}$. Essa intervenção externa era particularmente comum nos muitos casos envolvendo militares ou a Guarda Nacional, quando os atos da polícia podiam gerar sérios distúrbios. O problema principal eram os soldados, sempre dispostos a uma boa briga com a polícia ${ }^{28}$, às vezes envolvendo oficiais nas escaramuças. A tentativa de prender um desordeiro que era cabo da Guarda Nacional resultou no ataque a um policial militar, que foi levado para o quartel da Guarda. O comissário ali enviado para resolver o problema foi recebido com "palavras injuriosas e gestos obscenos, além da tentativa de soltarem cães bravios". Na confusão o policial militar fugiu e refugiou-se na delegacia, para onde se dirigiu o comandante do batalhão da Guarda Nacional, tenente-coronel Ismael da Cunha, despachante da Alfândega, que prendeu o delegado e dois comissários $^{29}$. Os manuais da polícia continham instruções especiais sobre a maneira de agir ao prender militares: era preciso contar com a presença de outro militar de patente igual ou superior supervisionando o processo, e cautela era sempre indispensável ${ }^{30}$. Estes problemas ficaram ainda mais evidentes nos anos20, quando jovens oficiais envolveram-se em movimentos contra o governo e tiveram de ser policiados ${ }^{31}$.

O poder do apadrinhamento também era evidente nos muitos casos de patrões preocupados com o comportamento de seus empregados, ou com o desaparecimento das muitas crianças indisciplinadas empregadas no serviço doméstico. Quando uma jovem doméstica foi detida com o seu namorado por comportamento suspeito - geralmente descrito como "procurando cantos escuros" - seu patrão, Dr. Bonifácio da Costa, solicitou à polícia que mantivesse o rapaz preso até que a moça fosse a exame médico. Ele explicou que se sentia responsável pela jovem pois a mãe dela a confiara à sua guarda ${ }^{32}$. O poder repressivo de um patrão podia mesmo superar o de um pai. Nas mesmas circunstâncias, Rosa da Silva, 18 anos, foi presa às 23 horas por estar "abraçados aos beijos" com seu namorado, o barbeiro português Afonso de Abrantes, pelos cantos escuros da Avenida Beira Mar. Quando seu pai foi chamado, ele disse que não dispunha de acomodações para a filha, e ia ver o que poderia fazer no dia seguinte ${ }^{33}$.

Crianças empregadas no serviço doméstico eram mantidas sob a vigilância de seus patrões/guardiães, situação bastante comum, e o fato de haverem constantes fugas indica que o relacionamento não era exatamente harmonioso. Quando Sebastião Martins Viana chegou na delegacia para se queixar que José, um pardinho de 6 anos, tinha fugido deixando sua casa abandonada, ele não sabia que o garoto tinha sido levado à delegacia três dias antes, explicando que fugira da casa do patrão porque recebia "muita pancada e pouca comida" 34 . O abuso sexual era outra possibilidade: quando a polícia foi chamada para cuidar de uma louca na rua Club Atlético 23, descobriu que a suposta louca era a furiosa Regina de Oliveira, uma órfã de 13 anos, recolhida àquela casa de família por ordem do Juiz de Órfãos. A menina se queixou das 
surras que levava da patroa e disse que tinha sido deflorada pelo irmão da dona da casa, um aluno de 16 anos do Colégio Militar, que lhe prometera como recompensa um bracelete de ouro ${ }^{35}$.

Casos como esses nos dão uma pista para compreendermos o relacionamento entre a polícia e as classes superiores e mostram que, quando as autoridades policiais tinham de agir contra a elite, o melhor a fazer era ignorar o caso. Mesmo quando havia a possibilidade de construir um caso, a polícia tinha de enfrentar muitos obstáculos. Depois de um guarda noturno ter prendido o Dr. Nelson Marcos Bezerra Cavalcanti - que deu como endereço seu escritório - por agredir sua amante na presença de duas testemunhas, o caso foi abandonado porque ela negou ter sido agredida ${ }^{36}$. A prisão do capitão da Guarda Nacional que mandou que o delegado "fosse a...(o comissário não ousou dizer onde)" foi recusada pela polícia militar e ele teve de ser transferido para o Corpo de Segurança ${ }^{37}$. Quando um cavalo pertencente a Escola de Comando e Estado Maior do Exército foi atropelado, o processo contra o motorista teve de ser arquivado porque era o filho de 15 anos de um coronel que estava montando o animal, e o oficial mandou desistir da queixa, deixando ao exército a perda do animal, antes de ter de responder em inquérito por que permitiu que seu filho saísse com o cavalo. À polícia só restou aceitar a determinação ${ }^{38}$.

A capacidade da polícia de arbitrar disputas e fazer valer suas decisões não podia ser sustentada frente a membros recalcitrantes das classes superiores, e tinha de depender de uma boa vontade nem sempre disponível. Quando Floriano Daltro Ramos, aluno do Colégio Militar, reagiu num bonde quando "numeroso grupo de carnavalescos, a maioria dos quais lograram se evadir, levaram ao ridículo o dito aluno, que não aceitando a versalhada com o tema, puxou de um revólver com a intenção de alvejar os seus perseguidores"; o delegado limitou-se a aconselhá-lo e restituir a arma. Dias depois, Carlos Daltro e Almério Daltro Ramos foram presos, envolvidos num caso muito confuso, em que forçaram um táxi a conduzí-los sob a mira de uma arma e em seguida tentaram estrangular um dentista num bonde. Provavelmente eram parentes de Floriano, em busca de vingança, o que parece se confirmar porque este apareceu logo em seguida na delegacia, "extremamente nervoso e nada dizendo que justificasse a sua presença. Pressentindo-o armado, fiz-lhe a apreensão de um revólver com cabo de madrepérola e carregado com cinco balas", que desta vez parece ter sido confiscada ${ }^{39}$. A incapacidade da polícia em resolver casos envolvendo a elite fica clara quando um dos proprietários do Hotel Fluminense se queixou do comportamento de um dos hóspedes:

Às 12:30 a.m. veio a esta delegacia o sr. Hercules Ribas sócio do Hotel Fluminense a Praça da Republica 207 queixar-se de que o seu hospede do quarto 70, Dr. Vieira de Moraes, se portava de forma inconveniente fazendo visitas noturnas ao quarto 14 , onde se acha hospedada Mme. Judith Marques de 
Azevedo esposa do Dr. Antonio Marques de Azevedo, engenheiro da Central ora ausente, isso com escândalo e protesto dos demais hóspedes, e como assim fosse o queixoso prejudicado pela retirada dos hóspedes, colocou um seu empregado no serviço de ronda para evitar maior escândalo, sendo seu empregado ameaçado pelo médico dr. Vieira de Moraes que dizendo armado de revólver insistia continuando as suas visitas, pelo que resolvera impedir sua entrada no estabelecimento.

Compareceu a esta delegacia o Dr. Vieira de Moraes pedindo garantias para penetrar no hotel, o que lhe foi concedido, sendo colocado um guarda civil para manter a ordem visto não se harmonizarem as partes insistindo o Dr. Moraes em declarar não só o que fizera como ainda continuar a proceder como bem entendesse ${ }^{40}$.

Um último exemplo pode mostrar bem como a polícia tinha de se render ante a superioridade de membros da elite, no caso da própria elite do estado ligada a segurança pública, bem como mostra que os tratamentos não eram iguais para todos. Na noite de 31 de março de 1917, às 23:30, Antônio Pereira foi conduzido à delegacia do $5^{\circ} \mathrm{DP}$ para pagar multa, por ter sido encontrado urinando no muro do Passeio Público. Mais tarde, às 3 horas da manhã, um guarda civil surpreendeu outro homem no mesmo local e circunstâncias ("com o membro de fora, a urinar no passeio" anotou o embaraçado comissário). A diferença foi que desta vez o infrator identificouse como Almiro de Campos, juiz da $3^{\text {a }}$ Pretoria Criminal, que declarou "ter assim procedido por ser esta a praxe existente nesta cidade". Também era praxe entre os poderosos escapar da lei, e ele telefonou para o $3^{\circ}$ Delegado Auxiliar, que ordenou sua imediata liberação ${ }^{41}$.

Recebido para publicação em março/1997

BRETAS, Marcos Luiz. Remarks about the failure of police models. Tempo Social; Rev. Sociol. USP, S. Paulo, 9(1): 79-94, May 1997.

ABSTRACT: This paper shows how the police took diverse organizational forms in national contexts, instead of producing in its agents everywhere a very similar world view. Centrally or locally organized, the men/women in charge express themselves in the same terms. We try to explain this trend by pointing to the daily experience of policing which are shared by all police forces, and where any explanation of police thinking must be sought. We present as example the daily activities of Rio de Janeiro's police in early twentieth-century, showing

UNITERIMS:

police, organizations, world view, elites. 
their relation with the elites and how they create at the same time the boundaries of police authority and the perception of the existence of certain groups against whom extra-legal means of pressure can be exerted.

\section{Notas}

${ }^{1}$ Parece-me entretanto que a definição da polícia a partir de suas key practices pode ser apenas uma limitação do conceito, e que análises de situações concretas e comparações são a forma de vencer estes limites.

${ }^{2} \mathrm{Na}$ verdade, este modelo cultural funciona quando é auto-aplicado, isto é, as diferentes culturas se reconhecem na apresentação do modelo. O outro lado é que existe também especialmente no cinema americano uma representação da polícia do outro, mostrando os horrores da polícia na América Latina. Nove entre dez vilões do cinema pretendem fugir para o Rio de Janeiro.

${ }^{3}$ A oposição dos modelos francês e inglês de polícia já é tradicional, mas simplificadora. Mesmo dentro desse espaço é preciso dar conta das diferenciações exigidas por tarefas de ocupação, como é o caso da ação inglesa na Irlanda, e mais tarde no seu império colonial.

${ }^{4}$ Esta diferenciação é apontada por Jean Paul Brodeur (cf. 1992). Ele nota como a tendência contemporânea é de ampliar o espaço de atuação policial.

${ }^{5}$ Um aspecto lateral, mas interessante, é notar que imagens da polícia também tendem a se tornar similares; a well established reputation for incompetence and for venality and corruption refere-se a CID inglesa. Cf. Barbara Weinberger (1995, p. 75), em que se pode encontrar uma longa lista de citações de policiais que poderiam ter sido coletadas em qualquer lugar.

${ }^{6}$ Para um bom resumo da cultura policial e das diferentes versões acadêmicas ver o capítulo III - Cop Culture, de Robert Reiner (1992).

${ }^{7}$ Num breve momento do início do século XX ocorreu uma tentativa por elementos da elite intelectual de assumir a direção dos trabalhos policiais, considerados como uma parte atraente do desenvolvimento científico da época. Essa vocação de intelectuais cariocas para vivenciarem Sherlock Holmes tupiniquins - não é por acaso que Elysio de Carvalho, cronista mundano e diretor de identificação da polícia, intitula sua coletânea de artigos sobre investigação policial Sherlock Holmes no Brasil (no caso o Sherlock do título é o criminólogo suíço Reiss) - durou muito pouco. Restou uma marcante atuação de médicos na área da medicina legal e da psiquiatria ligada ao crime, que forneceu elementos para o discurso policial, sem que no entanto tivessem reflexos mais profundos nas práticas policiais.

${ }^{8}$ A lei funciona para a polícia na forma que Peter Manning chamou estratégia de apresentação; em que o recurso aos impedimentos legais servem apenas para encaminhar a ação na direção desejada (cf. Peter Manning, 1977).

${ }^{9}$ Há alguns estudos desse tipo de caso, usados como situações em que os valores sociais são expostos e podem ser mais facilmente reconhecidos (cf. Benjamin Martin, 1984). A prática de absolver acusados de crimes passionais no Rio é o tema de Susan Besse (1989, p. 653-666).

${ }^{10}$ Bóris Fausto (1984, p. 17) nota a surpresa dos funcionários dos Arquivos da Justiça de São Paulo quando ele não se mostrou interessado nos grandes criminosos, preferindo consultar casos comuns.

${ }^{11}$ Essa tendência parece muito diferente do que foi encontrado por Clive Emsley na Inglaterra, que encontrou como principal problema o excesso de velocidade cometido por donos de carros. Aqui o problema são acidentes provocados por autos com motorista (cf. Clive Emsley, 1993). 
${ }^{12} \mathrm{O}$ chofer do sr. Afonso Vizeu atropelou e matou o menino de 6 anos Igor Praus na praça Saens Peña. O chofer fugiu - embora as testemunhas fossem a seu favor - enquanto o $\mathrm{Sr}$. Vizeu, que estava no carro com sua família, procurou providenciar os primeiros socorros para o menino (cf. ocorrências, $\left.17^{\circ} \mathrm{DP}, 03 / 04 / 1925\right)$. Em outro caso foi o chofer do Dr. Oswaldo Cruz (cf. ocorrências, $15^{\circ} \mathrm{DP}, 02 / 07 / 1913$ ). Às vezes essas testemunhas não se davam ao trabalho de comparecer à delegacia: o sr. Antonio Angélico Pereira enviou seu cartão para informar à polícia que seu motorista era inocente (cf. ocorrências, $15^{\circ} \mathrm{DP}, 08 /$ 02/1917).

${ }^{13}$ Cf. ocorrências, $15^{\circ}$ DP, 22/08/1921.

${ }^{14}$ Sobre a história da criminalização das drogas cf. Júlio César Adiala (1996).

${ }^{15}$ Em 13 de setembro de 1921 o comissário Pelayo Vidal visitou uma dessas casas, a fumerie do Beco dos Ferreiros 11, "um infecto cortiço, onde numa promiscuidade indescritível indivíduos de nacionalidade chinesa entregavam-se a absorção do ópio por meio de cachimbos de bambu, de várias espécies e feitios, em número de quatro, que foram por mim apreendidos e entregues ao Dr. delegado, bem como um pote de vidro contendo mais ou menos 30 gramas de uma massa preta com todas as características de ópio..." (ocorrências, $5^{\circ}$ DP, 13/09/1921).

${ }^{16}$ Os antros frequientados pelos fumadores de ópio forneceram um cenário perfeito para os cronistas da cidade como João do Rio, Benjamim Costallat e Luiz Edmundo. Eles também aparecem nos registros policiais: no dia 23 de maio de 1920, foi encontrado ópio na casa dos chineses João China, San José, Iuan May e Tan Gou, no Beco dos Ferreiros 22. No dia 17 de junho foi em outra casa da mesma rua, pertencente aos chineses Alo Pereira e A. Paulo. Em ambos os casos os chineses foram enviados ao Chefe de Polícia. O artigo 159 do Código Penal previa apenas uma multa para a venda ilegal de "substâncias venenosas". Somente em 6 de julho de 1921, por força do decreto 4.294, foi instituída a pena de prisão.

${ }^{17}$ Pernambuco Filho e Adauto Botelho estimam que dois terços das prostitutas faziam uso de cocaína. O consumo na elite aparecia ligado a seu relacionamento com a prostituição. A polícia encontrou o filho do procurador criminal do Distrito Federal sendo retirado às escondidas do prostíbulo onde se encontrava com sua amante, a meretriz italiana Bianca Fasetti, em coma provocada por ingestão de cocaína. O guarda civil local foi acusado de estar deliberadamente ignorando a ocorrência (cf. ocorrências, $13^{\circ} \mathrm{DP}$, 08/01/1924).

${ }^{18}$ Cf. ocorrências, $5^{\circ}$ DP, 20/08/1921. Nos primeiros anos da década de 1920, a repressão à cocaína aparece em ciclos. Ver, por exemplo, ocorrências, $12^{\circ} \mathrm{DP}, 22 / 12 / 1922$, e $13^{\circ}$ DP, 18/03/1924.

${ }^{19} \mathrm{Cf}$. ocorrências, $15^{\circ} \mathrm{DP}, 01 / 04 / 1909$. Para dimensionar corretamente os esforços da polícia, é preciso levar em conta que cada delegacia de um modo geral só dispunha de um agente para cuidar de todos os crimes contra a propriedade.

${ }^{20}$ Cf. ocorrências, $5^{\circ}$ DP, 25/06/1923.

${ }^{21}$ No dia $31 / 01 / 1913$, o delegado do $14^{\circ}$ DP ordenou a detenção de três homens, sem nenhuma acusação formal, depois de uma queixa apresentada no dia 27 pelo dono de uma tabacaria, de que os homens pretendiam assaltar sua loja. O dono da loja foi identificado como coronel Antenor - provavelmente um oficial da Guarda Nacional - e o delegado informou o $2^{\circ}$ Delegado Auxiliar sobre as prisões. O coronel Antenor devia ser um homem com muito boas ligações.

${ }^{22}$ João Manoel da Fonseca, viúvo, matou-se com um tiro por estar doente. Era porteiro do Arsenal de Marinha e Capitão honorário do exército. "O corpo ficou em casa a pedido da família" (Jornal do Commércio, 02/01/1909).

${ }^{23}$ Jornal do Commércio (09/02/1909).

${ }^{24}$ Jornal do Commércio (25/02/1909). No dia seguinte ainda era criticado o comissário do $6^{\circ} \mathrm{DP}$ por ignorar uma queixa de incêndio criminosos. Apesar das medidas de Alfredo Pinto "o velho mal parece zombar sem receios da terapêutica de sua retidão".

${ }^{25}$ Uma vítima de agressão foi a delegacia acompanhada pelo deputado A. A. Lamounier Godofredo, e o seu agressor foi preso (cf. ocorrências, $\left.12^{\circ} \mathrm{DP}, 12 / 11 / 1919\right)$. 
${ }^{26}$ Cf. ocorrências, $5^{\circ}$ DP, 30/03/1915.

${ }^{27}$ No dia 17 de junho de 1923, um engenheiro agrimensor compareceu ao $14^{\circ}$ DP para dar queixa de que um agente e dois soldados da Polícia Militar estavam espancando um trabalhador num bar. O comissário registrou que os policiais já tinham estado ali, e "sem nenhuma explicação, processo aliás conhecido para evitar o conhecimento desses excessos, pretendia deixar o preso Henrique José de Souza a disposição do exmo. sr. mal. chefe de polícia, ao que me opus, fazendo com que o mesmo o levasse para a polícia central" (ocorrências, $14^{\circ} \mathrm{DP}, 17 / 06 / 1923$ ).

${ }^{28}$ Casos de conflito entre a polícia e soldados eram muito frequientes. Quando dois guardas civis trouxeram uma família, "por terem reclamado o modo inconveniente como foram tratados por um sargento do exército, um cabo e uma praça da mesma corporação, que viajavam no mesmo trem. Nesta delegacia disseram que o sargento além de portar-se inconvenientemente dirigindo chalaças a uma sua filha, deu ainda um tiro, saltando do trem na estação de São Cristóvão, tendo os dois últimos prosseguido até a Praça da República, onde os guardas tomaram conhecimento. As duas praças, ao serem intimadas a vir à delegacia, desrespeitaram os guardas, conseguindo assim que viessem em sua companhia mais praças e algumas a paisana. As praças em número de 15 nesta repartição portaram-se inconvenientemente querendo a viva força promover um conflito que a muito custo e por meios suasórios consegui evitar, deixando por esta razão de tomar os números das mesmas, visto não ter força suficiente para tornar efetiva qualquer deliberação. Mais tarde pedi providências ao $2^{\circ}$ DA que mandou uma força composta por 10 praças, 40 minutos depois de pedida" (ocorrências, $14^{\circ} \mathrm{DP}, 05 / 01 / 1913$ ).

${ }^{29}$ Cf. ocorrências, $19^{\circ}$ DP (10/01/1917) e Jornal do Commércio (11/01/1917). Alguns dias depois, a mesma delegacia prendia por desordem e embriaguez um indivíduo que declarou ser o tenente coronel comandante do $109^{\circ}$ Regimento de Cavalaria da Guarda Nacional, com sede em Nioac (cf. ocorrências, $19^{\circ}$ DP, 31/01/1917).

${ }^{30}$ Os problemas criados pela prisão de militares eram percebidos por outros criminosos. Jogadores profissionais freqüentemente adquiriam patentes de oficial da Guarda Nacional, tornando muito mais difíceis os procedimentos para sua prisão.

${ }^{31}$ O Capitão-Tenente da marinha Eduardo Henrique Sisson pode ser apontado como exemplo de oficial problema. O seu nome aparece duas vezes nos livros de ocorrências, acusado de desordem em estado de embriaguês de madrugada. Na primeira vez ele agrediu o dono da charutaria do Café Tavares com uma caixa de charutos, e na delegacia insultou do comissário de serviço ao presidente da república. Ele foi preso novamente seis meses depois, no Club dos Políticos, se referindo "nos termos mais insultuosos que admitir se possam às pessoas dos Srs. Presidente da República, Almirante Alexandrino e Mal. Chefe de Polícia. Acredito que fosse em parte, a desorientação motivada pelo estado alcoólico em que o mesmo se encontrava a causa principal das lamentáveis cenas aqui ocorridas, mas também estou certo de que esse oficial aproveita esse estado de alcoolismo, para praticar atos dessa natureza, e dar assim, [ilegível] ao seu espírito de odiosidade as autoridades constituídas, parecendo-me até ser ele um revoltoso perigoso, que para bem da ordem pública, necessita ser retirado de nosso meio populoso, independente da punição severa a que faz juz, para decoro de sua classe" (ocorrências, $5^{\circ}$ DP, 03/08/1924 e 22/02/ 1925).

${ }^{32} \mathrm{Cf}$. ocorrências $\left(12^{\circ} \mathrm{DP}, 02 / 12 / 1919\right)$. Em outro caso, um patrão informou à polícia que sua empregada deixara sua casa: "Resolvera informar as autoridades porque ele trouxera a jovem do interior e se sentia responsável, embora ela fosse maior de idade" (ocorrências, $\left.14^{\circ} \mathrm{DP}, 23 / 04 / 1923\right)$.

${ }^{33}$ Cf. ocorrências (5 DP, 23/04/1915). Rosa, como outras empregadas domésticas, havia ultrapassado a hora do "toque de recolher", e não podia retornar à casa onde trabalhava. Segundo ela, quando isso acontecia, dormia na casa de amigos de seu pai.

${ }^{34}$ Cf. ocorrências ( $19^{\circ}$ DP, 25/02/1925 e 01/03/1925). O quadro das condições de vida dos menores no serviço doméstico era estarrecedor. Manoel, um menino negro de 11 anos, tinha sido trazido de Cantagalo para trabalhar na casa de um general, de onde fugiu; Djanira Presciliana, preta, 15 anos, viera de Campos e tentara se suicidar porque não lhe permitiam voltar (cf. ocorrências, $17^{\circ}$ DP, 05/01/1925 e 24/01/1925). Alice Martucci, 13 anos, chegara há dois dias de Porto das Caixas e também queria voltar; Dolores Vidal, 16 
anos, fugiu da casa do delegado do $24^{\circ} \mathrm{DP}$; Francisco, pardo, 14 anos, fugiu da casa do Dr. Nelson de Vasconcelos, depois de ali trabalhar por sete anos (cf. ocorrências, $17^{\circ} \mathrm{DP}$, 10/02/1917; 03/03/1917 e 14/03/1917). Dona Maria Celestina perdera suas três empregadas no que parecia uma fuga em massa; ela as descreve em termos que fazem lembrar o mercado de escravos: Almerinda, preta, 17 anos, robusta, bons dentes, cabelo quase liso; Leonor, 13 anos, morena clara, cabelos crespos, simpática, bons dentes, compleição frágil; e Alzira, parda, robusta, cabelo carapinha (cf. ocorrências, $15^{\circ} \mathrm{DP}, 13$ / 09/1921).

${ }^{35}$ Cf. ocorrências (17 $\left.\mathrm{DP}, 06 / 11 / 1922\right)$. Outros exemplos são Esmeraldina, 17 anos, desonrada pelo filho do patrão (cf. ocorrências, $17^{\circ} \mathrm{DP}, 10 / 02 / 1925$ ), e Dolores Maria Rosa, que acusou seu patrão, comandante Álvaro Bastos, de ter abusado dela sob ameaça de morte. Ignorando completamente as circunstâncias violentas, o caso foi encerrado porque ela era maior de idade (cf. ocorrências, $12^{\circ}$ DP, 21/03/1921).

${ }^{36}$ Cf. ocorrências (12 DP, 11/01/1925).

${ }^{37}$ Cf. ocorrências ( $5^{\circ}$ DP, 06/03/1915).

${ }^{38}$ Cf. ocorrências (19º DP, 15/06/1925).

${ }^{39}$ Cf. ocorrências (19º DP, 09 e 18/02/1925).

${ }^{40} \mathrm{Cf}$. ocorrências (14 $\left.{ }^{\circ} \mathrm{DP}, 18 / 03 / 1913\right)$.

${ }^{41}$ Cf. ocorrências ( $\left.5^{\circ} \mathrm{DP}, 31 / 03 / 1917\right)$. O mesmo juiz volta a aparecer na noite de natal de 1919. Um soldado atendeu a uma queixa às 2:40 da manhã sobre gritos vindo de uma casa. Eis que surge o juiz e explica, injuriando o policial, que tivera uma cena de ciúmes com sua amante no Palace Theatro, e que depois de chegarem em casa ela tivera um ataque. $\mathrm{O}$ comissário deixou claro no seu registro que lamentava a atitude do juiz com o rondante, mas não mostrou nenhum interesse em saber se o juiz estaria ou não espancando a amante (cf. ocorrências, $\left.13^{\circ} \mathrm{DP}, 25 / 12 / 1919\right)$. Um caso absolutamente idêntico, em que a polícia teve que se desculpar com um juiz depois de prendê-lo por estar urinando numa rua da Cidade do México, é narrado por Laurence J. Rolphe (1983).

\section{REFERÊNCIASBIBLIOGRÁFICAS:}

AdIALA, Júlio César. (1996) A criminalização dos entorpecentes. Dissertação (Mestrado). Rio de Janeiro, IUPERJ.

BAYLEY, David H. (1992) Comparative organization of the police in englishspeaking countries. In: ToNRY, Michael \& MoRRIS, Norval. Modern policing. Chicago, University of Chicago Press. p. 509-546.

BEsSE, Susan. (1989) Crimes of passion: the campaign against wife killing in Brazil, 1910-1940. Journal of Social History, 22 (4): 653-666, summer.

Brodeur, Jean Paul. (1992) High policing and low policing: remarks about the policing of political activities. In: McCormick, Kevin R. E. \& VISANO, Livy A. Understanding police. Toronto, University of Toronto Press, p. 277-299.

BROGDEN, Mike. (1987) The emergence of the police - the colonial dimension. British Journal of Criminology, 27: 4-14.

CAIN, Maureen. (1992) Trends in the sociology of police work. In: McCoRMICK, Kevin R. E. \& VISANO, Livy A. Understanding police. Toronto, University of Toronto Press. p. 3-32. 
Emsley, Clive. (1993) Mother, what did policemen do when there weren't any motors? The law and the regulation of motor traffic in England, 1900-1939. The Historical Journal, p. 357-381.

Fausto, Bóris. (1984) Crime e cotidiano: a criminalidade em São Paulo (1880-1924). São Paulo, Brasiliense.

Manning, Peter. (1977) Police work. Cambridge, Mass, Cambridge University Press.

Martin, Benjamin. (1984) The hipocrisy of justice in the belle époque. Baton Rouge, Louisiana State University Press.

Palmer, Stanley. (1988) Police and protest in England and Ireland, 17801850. Cambridge, Cambridge University Press.

Pernambuco Filho \& Botelho, Adauto. (1924) Vícios sociais elegantes. Rio de Janeiro, Livraria Francisco Alves.

REINER, Robert. (1992) Cop culture. In: The politics of the police. $2^{\text {nd }}$ edition. Toronto, The University of Toronto Press. p. 107-137.

RolPHE, Laurence J. (1983) Police and penal correction in Mexico city, 18761911: a study of order and progress in Porfirian Mexico. Tese (Doutorado). Tulane University.

SindaLl, Rob. (1983) Middle-class crime in nineteenth-century England. Criminal Justice History, 4: 23-40.

SKOLNICK, Jerome H. (1966) Justice without trial. Law enforcement in democratic society. New York, MacMillan.

VADACKUMCHERY, James. (1996) Human rights and the police in India. New Delhi, APH Publishers Corporation.

Weinberger, Barbara. (1995) The best police in the world. An oral histoty of enghish policing from the 1930's to the 1960's. Aldershot, Scolar Press. 